\title{
Retraction Note to: Associations of IL-8 gene polymorphisms and IL-8 levels with predisposition to age-related macular degeneration: a meta-analysis
}

\author{
Jianhui Liu ${ }^{1}$ - Zhiqing Tian ${ }^{1}$. Jinhui $\mathrm{Li}^{1}$ • Guangming Zhao ${ }^{2}$
}

Published online: 27 October 2020

(c) Springer Nature Switzerland AG 2020

\section{Retraction to: Aging Clinical and Experimental Research https://doi. org/10.1007/s40520-020-01501-7}

The authors have retracted this article [1] because it overlaps with an unpublished article by Zulvikar Syambani Ulhaq. All authors agree to this retraction.

\section{Reference}

1. Liu J, Tian Z, Li J et al (2020) Associations of IL-8 gene polymorphisms and IL-8 levels with predisposition to age-related macular degeneration: a meta-analysis. Aging Clin Exp Res. https://doi. org/10.1007/s40520-020-01501-7

Publisher's Note Springer Nature remains neutral with regard to jurisdictional claims in published maps and institutional affiliations.

The original article can be found online at https://doi.org/10.1007/ s40520-020-01501-7.

Guangming Zhao

zhaoguandidne@163.com

1 Department of Ophthalmology, Changyi People's Hospital, Changyi 261300, Shandong, China

2 Department of Ophthalmology, Zhuji Affiliated Hospital of Shaoxing University, Zhuji 311800, Zhejiang, China 